\title{
Urban transport infrastructure planning and the public interest: a public health perspective
}

\section{Tomas James Robertson"a,c, Abigail McCarthya , Edward Jegasothya and Patrick Harris ${ }^{b}$}

a School of Public Health, University of Sydney, NSW, Australia

b Centre for Health Equity Training, Research and Evaluation, UNSW Sydney, Australia

c Corresponding author: trob7144@uni.sydney.edu.au

\section{Article history}

Publication date: June 2021

Citation: Robertson TJ, McCarthy A, Jegasothy $E$, Harris $P$. Urban transport infrastructure planning and the public interest: a public health perspective. Public Health Res Pract. 2021;31(2):e3122108. https://doi.org/10.17061/phrp3122108

\section{Key points}

- Large transport infrastructure projects should be executed in the public interest

- We studied submissions to an inquiry into the impact of the motorway project WestConnex, Australia's largest infrastructure project

- The health impact of the project was the central concern in submissions from the public and organisations

- The findings suggest comprehensive health analyses should be included in business cases and environmental impact statements in early stages of planning major infrastructure projects

\section{Abstract}

Objective: Transport infrastructure impacts public health. WestConnex in Sydney, New South Wales (NSW), is Australia's largest and most expensive transport infrastructure project. Concerns about the motorway project resulted in a NSW parliamentary inquiry into the project's impacts. Submissions to the inquiry were analysed to investigate their emphasis on health impacts and the cost-benefit analysis underpinning the project's business case.

Study type: Quantitative content and qualitative thematic analysis.

Methods: There were 556 submissions made to the inquiry into the impact of the WestConnex project. The content of a random sample of $93(20 \%)$ of the individual submissions was analysed to identify health concerns. A purposive sample of 81 submissions by named groups including political parties and organisations was analysed separately (15\% of the total submissions).

Results: Most individual submissions (63\%) mentioned at least one aspect of health. Air pollution and children's health were the most frequently mentioned health issues. In the purposive sample, most submissions (64\%) concerned the cost-benefit analysis (CBA), including concerns that the health impacts were being underestimated and economic benefits overestimated in the CBA.

Conclusions: This study on the WestConnex project demonstrates how health impacts require early consideration within business cases for urban infrastructure projects, and later during environmental impact assessment. Systems for communicating and involving the public in decision making need to be improved, alongside greater transparency in CBA early in the project planning cycle. 


\section{Introduction}

Internationally, cities are facing burgeoning growth in transport mega-projects to deal with increasing population growth. These projects are often highly politicised due to their financial costs to the public and the distribution of their social, environmental and economic impacts both in construction and operational phases. Transport infrastructure affects human health, through changes to mobility, physical activity, air pollution, noise pollution and community connectedness. ${ }^{1}$

The planning of such projects, particularly environmental assessment processes and documentation, has been consistently shown to insufficiently consider health impacts. ${ }^{2}$ Environmental assesment may occur relatively late in project planning, depending on the location of the project, therefore potentially precluding consideration of the range of health impacts in the decision-making and options-appraisal phases. ${ }^{3}$

WestConnex is Australia's most expensive transport infrastructure project, designed to ease congestion and connect Sydney's west and south west with the central city, airport and ports. ${ }^{2}$ It is a motorway project, including extensions and upgrades of existing infrastructure and the construction of new motorways and underground tunnels. ${ }^{4}$ WestConnex is expected to cost almost \$AUD20 billion²; such significant government spending requires funds to be appropriately allocated and community concerns addressed.

A New South Wales (NSW) parliamentary inquiry was established 21 June 2018 by the Legislative Council Public Accountability Committee to report on the impacts of the project. The inquiry called for submissions from the public regarding WestConnex, including the adequacy of the business case, its cost and compulsory acquisition of property. ${ }^{5}$ This inquiry invited investigation of how WestConnex was planned in relation to the public interest and how public health issues formed part of that public interest.

\section{Methods}

Submissions were received between 21 June 2018 and 31 August 2018 via a form on the NSW Parliament Public Accountability Committee website. Submissions were first quantitatively analysed before being qualitatively analysed based on emerging themes.

In total, 556 submissions were received and were split into two groups: 475 submissions by individuals, and 81 submissions by organisations or people writing in a professional capacity. A random sample of submissions by individuals ( $n=93$ or $20 \%$ of submissions by individuals) was chosen by assigning sequential numbers to submissions and using random number generation software to chose selected submissions. The random sample was chosen to examine community wellbeing concerns and the level of concern regarding the costbenefit analysis (CBA) of WestConnex.

A separate, purposive sample ( $n=81,15 \%$ of total submissions) was selected to examine the level of concern regarding the CBA of WestConnex. Purposive submissions were classified as those made by groups such as political parties, politicians, doctors and organisations. The purposive sample was chosen because of the expected partiality in their views, with opposition to the ongoing WestConnex project expected.

Content analysis was conducted using NVivo software (Melbourne, Australia: QSR International; NVivo 11). First, the frequency of the term "health" was identified in the random sample. Second, the frequency of the terms: "cost", "cost-benefit" and "costing" were identified in both the random and purposive samples. Manual thematic analysis was then conducted by two authors ( $A A$ and $B B$ ) to identify emergent themes within health and CBA issues respectively. Ethics approval was not required due to the public availability of data.

We analysed the different health themes that emerged from the analysis, the specific areas within CBA and the procedural aspects of the CBA that were of concern. Quotes are used where possible to accurately reflect the emotive language used in some submissions. Submissions have been deidentified and are listed by their submission number (1-556). Submissions can be found at the NSW Parliament website. ${ }^{6}$

\section{Results}

\section{Content analysis}

"Health" was raised as a concern in almost half (44\%) of submissions within the random sample. Table 1 shows the subcategories of health that were raised within the random sample submissions. The subcategories are broken down into the number of submissions each issue was mentioned in and as a percentage of submissions in the random sample.

Submissions could mention more than one subcategory of health and those submissions which mentioned a subcategory of health multiple times were only counted once. The most prevalent concerns were air pollution and children's health, as shown in Table 1.

CBA was frequently mentioned within both the random and purposive submissions. Out of the purposive samples, 52 (64\%) mentioned "cost", "cost-benefit" or "costing", while in the random sample this theme was mentioned in only $40(43 \%)$ of submissions. This highlights procedural concerns about WestConnex within the purposive submissions. 
Table 1. Health concerns expressed in the random sample of public submissions to the parliamentary inquiry into WestConnex

\begin{tabular}{lcc}
\hline Theme & $\begin{array}{c}\text { Submissions } \\
(n=93)\end{array}$ & $\begin{array}{c}\text { Overall } \\
\%\end{array}$ \\
\hline Air quality/air pollution & 59 & $63 \%$ \\
Children's health & 30 & $32 \%$ \\
Stress/anxiety/mental health & 21 & $23 \%$ \\
Noise & 21 & $23 \%$ \\
Dust & 17 & $18 \%$ \\
Social cohesion and & 16 & $17 \%$ \\
community wellbeing & & \\
Disturbed sleep & 14 & $15 \%$ \\
Traffic danger & 13 & $14 \%$ \\
Lack of health-related & 8 & $9 \%$ \\
information & & \\
Loss of physical activity & 4 & $4 \%$ \\
\hline
\end{tabular}

Note: Submissions frequently mentioned more than one health concern

\section{Qualitative thematic analysis}

\section{WestConnex health concerns}

Air pollution was the health concern most frequently identified in individual submissions (63\% of the random sample), with dust from the construction process and future exhaust stack emissions of particular concern.

"The lack of height of the stack means exhaust from the stack will cover the suburb with dangerous chemicals and dust, opening the government to a huge law suit, not to mention making us very sick." (0208)

Submissions extended beyond individual perception and anecdotes. Some were critical of the technical specifications of the tunnel infrastructure, citing health concerns about air pollution exposure.

"The Rozelle Interchange involves the construction of four exhaust stacks in a residential area. One exhaust stack in an area is concerning enough but four - all unfiltered - in one area is unconscionable.

The health risks from emissions in excess of

50 tonnes of carcinogenic material each year are obvious." (0106)

Several submissions that mentioned air pollution also mentioned the second most common health theme, child health. The comments occasionally overlapped in their discussion of air pollution and child health. The submissions reflected concern that air pollution is more dangerous to children, or that the lives of children are of unique value.
"It will put thousands of young children at risk by exceeding the allowable air pollution levels." (0408)

Children's health was the second most mentioned health theme in the random sample submissions (32\%). These submissions contrasted with those regarding air pollution in their greater subjectivity and use of emotive language.

"The proposed exhaust stacks in the Rozelle area must never be allowed to go ahead with schools, day centres and homes in such close proximity." (0050)

Similarly to air pollution, children's health was a concern relating to both the construction phase of WestConnex and its future use. Concerns related to construction were widespread and heterogenous. Submissions suggested some parents had already elected to change their children's school due to health concerns.

"There are concerns among parents in local schools about the air quality given the nearness of the road and construction site. Some people have removed their children from [the local] public school." (0483)

Mental health, particularly stress and anxiety, was the third most common health theme alongside noise, with each identified in $23 \%$ of the random sample submissions. The mental health of residents close to construction and final locations of the project was the most common mental health topic raised. Concerns about the project's impact on residents' mental health fell into three major categories: financial loss due to a decrease in property value; removal from place of living by the compulsory acquisition of houses; or having to move due to intolerable living conditions.

"They were retired and lived off the rent without the need to claim pensions. Their forward planning was lost. This man cried when talking to me". (0176)

Noise pollution was also mentioned in $23 \%$ of submissions, with noise during the day mentioned by some individuals, but noise at night and on the weekends the concern most commonly raised.

"We constantly hear jackhammer kind of noises at all times of the day and even in the evenings and weekends." (0021)

Dust, loss of physical activity and traffic danger were inter-related themes and were identified within $18 \%, 4 \%$ and $14 \%$ of submissions respectively. Dust from the construction phase has been reported to have had a significant impact on the ability of those close to construction to engage in physical activity; some have reported staying inside due to the accumulated dust. An increase in motor vehicle road use was also seen as a negative as it could result in decreased physical activity levels in contrast to 'active transport' alternatives. 
Traffic danger was also of concern, particularly for young children outdoors.

"The sheer amount of dust and dirt has prohibited myself and family members from using our outdoor area and we are forced to keep windows and doors closed." (0479)

Social cohesion and community wellbeing were raised in $17 \%$ of the random sample of submissions. Some individuals believed these indirect health impacts were being underestimated by the government. Submissions focused on the social implications that such a massive construction and infrastructure project can have, including forcing some residents to relocate.

"We used to be a community of happy people, but now we don't smile at each other anymore. We are a shattered, broken community. We all lack sleep and feel cheated by our government. Many people have left [the community], I don't blame them." (0208)

Finally, a lack of health information was highlighted in $9 \%$ of random sample submissions. As also seen within the purposive sample findings detailed below, health information was considered opaque and some submissions suggested that governmental decision makers were purposely withholding information from the public.

"As citizens, it is extremely difficult to find out clear and accessible information on the WestConnex project and its impacts, which is disturbing given it is the biggest infrastructure project in the Southern Hemisphere... Why are not meaningful air quality monitoring measurements made publicly available?" (0246)

\section{Concerns with the WestConnex business case}

Thematic analysis of submissions in the purposive sample identified three main themes concerning the business case behind the project. The first was that there was no comparison with other projects. Submissions highlighted concerns that the business case did not present sufficient alternatives for a road transport infrastructure project.

"These difficulties with the business case point to a larger concern about WestConnex and the way the project has been developed. It is based on an assumption that the project was required; that Sydney needed more toll roads to the exclusion of public transport... We know that the NSW Cabinet was directed away from public transport options to think only about private transport options." (0436)

The second major theme identified in purposive submissions was the underestimation of health impacts in the planning of WestConnex. Specifically, submissions felt that they were being treated impersonally and that government regulators were not empathising with genuine community wellbeing concerns.
"My faith in government processes has been significantly shaken in realising how little the lives and neighbourhoods of my local community matters to those making decisions about this project". (0244)

The third and final theme identified within the purposive sample was the overestimation of benefits. Specifically, demand for a road infrastructure project and forecast travel time savings due to WestConnex were the areas of most concern regarding overestimation.

"The inclusion of hypothetical travel time savings in urban transport business cases is controversial, because there is no empirical evidence that travel times decline in practice." (0250)

\section{Discussion}

This study of inquiry submissions has revealed the mismatch between the health concerns of the public and the planning process for public infrastructure. Our investigation into public submissions to the NSW Parliamentary inquiry on the WestConnex project has demonstrated how health is a primary concern in the community, compounded by perceived inadequacies with the planning process. This disconnect between community expectations and the planning process during WestConnex has been observed by others. ${ }^{7}$ By combining the results from the random and purposive samples, it is evident that three key areas need to be addressed in planning future transport infrastructure projects.

The first is the community perception of risk for major infrastructure projects. Clearly, despite 6 years of planning, there is still significant community concern regarding the health impacts of WestConnex. The purposive sample also suggested that the incorporation of externalities of health, such as social and community health, were inadequately accounted for in the planning behind the project. Submissions in both samples suggested that the environmental impact statement (EIS) should be expanded to incorporate a broader range of factors, specifically those that impact health. This suggestion has previously been noted by others ${ }^{8}$, with some attempting to deal with the additional domains ${ }^{9}$, yet, so far, no framework for valuing a broad range of health impacts is consistently required in EISs.

The NSW parliamentary committee responsible for the inquiry handed down 27 recommendations as a result of their findings. ${ }^{10}$ Most notably, recommendation 2 stated:

"That the NSW Government mandate the completion of a public health impact analysis as part of a wider economic analysis undertaken for future large scale infrastructure projects. "10

In response to this recommendation, the NSW Government argued that these public health concerns were already addressed within the WestConnex EIS 
and the EIS was complementary to the business case process. ${ }^{11}$ However, the EIS only includes specific aspects of health directly affected by 'construction and operational' stages of the project - mainly air quality which was assessed based on the data already used to model the transport impacts of the project. ${ }^{12}$ As the scope of the EIS is limited to include only a narrow definition of health within the construction and operational phases, an opportunity has been missed to include the external aspects of health described above, which are important to the community.

Another concern is that the public health impacts of a project of this size are only being considered in the EIS, which occurs as a separate process towards the end of the business case. This tendency is noted in other articles on infrastructure planning ${ }^{2,13}$, with public health and health impacts in general being considered late in the planning process. This is a concern for two reasons. The first is that health is seen as a secondary outcome in planning, as a 'spill-over' effect of infrastructure rather than core issue. ${ }^{13}$

The second, and most notable in submissions to the inquiry, is that this method of planning does not place the concern of communities at the forefront of political decision making. If the community and health are considered earlier in the planning process there are myriad of advantages, including those summarised succinctly by Infrastructure Australia in releasing its 2019 Australian Infrastructure Audit ${ }^{14}$ :

\section{"Better engagement with communities and businesses can help to establish a social licence for projects as it provides an opportunity to incorporate their feedback through project planning and delivery". ${ }^{14}$}

The second area of improvement is the structure for the consideration of health as part of the public interest during project planning. If there is a difference between the acceptable level of risk for adverse health outcomes perceived by members of the community compared with government organisations, then it will be necessary to involve members of the community earlier in the planning stages of the project. A more deliberative process may be needed such as the use of citizens' juries very early on, as part of options appraisal, or at a higher strategic planning level for infrastructure across cities and jurisdictions. ${ }^{15}$

However, the strategy of citizens' juries would likely not be sufficient to ensure public satisfaction with transport infrastructure projects and would need to be adopted alongside other measures. Boholm's work on risks and hazards provides some insight into the experience of those raising concerns about WestConnex. ${ }^{16}$ The differentiation between hazard and risk in the case of WestConnex is that local residents and members of the public are exposed to hazards by external factors whereas government agencies are exposed to risk which are caused by internal decisions. ${ }^{16}$ This causes a perspective shift between residents and government agencies, with each party perceiving the health risks of WestConnex in different ways. It is important to acknowledge this and let this guide communication to residents. The ways in which politicians and government agencies should involve the public and communicate findings is out of the scope of this study. However, transparency is a logical starting point that has been suggested by others as a key factor in public perception of political decision making. ${ }^{17}$

The third and final area is the transparency of the WestConnex planning process, particularly in the CBA. The original source of this lack of transparency in relation to WestConnex was that in the 2012 NSW State Infrastructure Strategy, no project alternatives to a roadway were considered. ${ }^{18}$ The extent to which Infrastructure NSW did not consider alternative infrastructure projects is highlighted in its State Infrastructure Strategy which states:

"In the absence of significant local population increases, demand on Sydney's bus corridors will be insufficient to justify new heavy rail or metro style rail on these corridors over the next 20 years. "19

The evidence regarding this statement is questionable. As of 2017 Sydney's population was growing at a rate of more than 100000 per year, a growth rate of $2 \% .{ }^{20}$ Sydney's growth rate is well above the world average of $1.2 \%$ and is one of the highest in the organisation for economic cooperation and development (OECD). ${ }^{21}$ The latest evidence suggests that expanding cities need to build public transport infrastructure, not roads, in order to keep pace with the travel demands of the increased population. ${ }^{22}$ This contradicts the information supplied by Infrastructure NSW and suggests that either no alternative transport methods were discussed or only a superficial examination of Sydney's transport needs was made. This is confirmed by a recent analysis of all major transport infrastructure projects in NSW, which found $56 \%$ of NSW election transport infrastructure commitments in 2019 recommended by Infrastructure NSW or Infrastructure Australia were either not backed by a business case or had no publicly released business case. ${ }^{23}$

Moreover, as mentioned in submissions in the purposive sample, the benefits of major transport infrastructure projects are often overestimated and forecasting needs to be more transparent. Globally, major transport infrastructure projects overestimate benefits, especially in travel time reduction, as road transport demand is, on average, underestimated by $9 \% .{ }^{24}$

WestConnex and its clear limitations as laid bare in the inquiry demonstrate the need for health to be an objective in the legislation governing significant state infrastructure projects. Such an objective has previously been considered in NSW, but subsequently abandoned. ${ }^{25}$ 


\section{Limitations}

There are several limitations to our study that may impact the results. In the random sample, 27 (29\%) authors listed their title as "name suppressed". This may have impacted on the results as these authors could be from a named group, in which case they should have been excluded from the random sample.

Some submissions had similar formatting and wording indicating that they may have been copied or produced communally. There were no exclusion criteria set for similar submissions as it was believed that authors still held the belief in their submissions, however, there may have been multiple minor discrepancies between their beliefs and their submissions.

Bias against WestConnex may also have been present in submissions. As WestConnex is already under construction, proponents of WestConnex may not have felt it necessary to submit to the NSW Parliament.

\section{Conclusions}

The analysis of submissions to the inquiry into the WestConnex project give rise to three conclusions. The first is that there needs to be greater consideration of the full range of potential health impacts for major infrastructure projects. This may include the incorporation of a broader definition of health within the CBA and EISs at an earlier stage of the planning process. Business cases need improving to include health externalities in the public interest.

The second is that systems that prompt the consideration of health in major infrastructure projects need improvement. Community consultation needs to occur earlier as part of a more deliberative process - use of citizens' juries is one such example.

Finally, a lack of information and detail about consideration of alternative infrastructure projects, that is available to the public, was noted in many submissions. Transparency across planning, and serious consideration of public consultation, particularly in CBAs for project, are needed when such significant amounts of public money are being spent.

\section{Peer review and provenance}

Externally peer reviewed, not commissioned.

\section{Competing interests}

None declared.

\section{Author contributions}

TR identified concerns with the CBA in the random and purposive samples, collated and organised data and information from other authors, and edited the manuscript.
AM identified health concerns within the random sample, edited the manuscript and provided guidance. EJ provided guidance and edited the manuscript and $\mathrm{PH}$ provided guidance, edited the manuscript and gave instructions for publication.

\section{References}

1. Giles-Corti B, Vernez-Moudon A, Reis R, Turrell G, Dannenberg $\mathrm{AL}$, Badland $\mathrm{H}$, et al. City planning and population health: a global challenge. Lancet. 2016;388(10062):2912-24.

2. Harris P, Riley E, Sainsbury P, Kent J, Baum F. Including health in environmental impact assessments of three mega transport projects in Sydney, Australia: a critical, institutional, analysis. Environmental Impact Assessment Review. 2018;68:109-16.

3. Commission of the European communities. Report from the Commission to the Council, the European Parliament, the European Economic and Social Committee and the Committee of the Regions. Brussels: European Union; 2009 [cited 2019 Oct 31]. Available from: www.ec.europa. eu/transparency/regdoc/rep/1/2009/EN/1-2009-378EN-F1-1.Pdf

4. Sydney Motorways Project Office. WestConnex business case executive summary. Sydney: Sydney Motorways Project Office; 2013 [cited 17 Feb 2019]. Available from: www.westconnex.com.au/media/ixebloea/westconnexbusiness-case-executive-summary-september-2013.pdf

5. Parliament of NSW Public Accountability Committee. Inquiry into the impact of the WestConnex Project. Sydney: Parliament of NSW; 2017 [cited 2018 Dec 17]. Available from: www.parliament.nsw.gov.au/lcdocs/ inquiries/2497/Terms\%20of\%20reference\%20-\%20 Inquiry\%20into\%20the\%20impact\%20of\%20the\%20 WestConnex\%20Project.pdf

6. Parliament of NSW. Impact of the WestConnex project. Sydney: Parliament of NSW; 2018 [cited 2019 Feb 21]. Available from: www.parliament.nsw.gov.au/committees/ inquiries/Pages/inquiry-details.aspx?pk=2497\#tabsubmissions

7. Haughton G, McManus P. Participation in postpolitical times: protesting Westconnex in Sydney, Australia. Journal of the American Planning Association. 2019;85(3):321-34.

8. Harris PJ, Harris E, Thompson S, Harris-Roxas B, Kemp L. Human health and wellbeing in environmental impact assessment in New South Wales, Australia: auditing health impacts within environmental assessments of major projects. Environmental Impact Assessment Review. 2009;29(5):310-18.

9. Button K. Environmental externalities and transport policy. Oxford Review of Economic Policy. 1990;6(2):61-75. 
10. Parliament of NSW. Public Accountability Committee. The impact of the WestConnex Project. Sydney: Parliament of NSW; 2018 [cited 2019 Sep 19]. Available from: www. parliament.nsw.gov.au/lcdocs/inquiries/2497/Final\%20 report\%20-\%20Impact\%20of\%20the\%20WestConnex\%20 Project\%20-\%20FINAL\%20-\%2014\%20December\%20 2018.pdf

11. NSW Government. The Hon Andrew Constance MP Minister for Transport and Infrastructure. NSW Government response. Inquiry into the impact of the WestConnex project. Sydney: NSW Government; 2019 [cited 2021 Apr 13]. Available from: www. parliament. nsw.gov.au/lcdocs/inquiries/2497/Government\%20 response\%20-\%20WestConnex.pdf

12. NSW Government. The Department of Planning Industry and Environment. WestConnex - M4-M5 Link Sydney, NSW 2018 [cited 2021 May 19]. Available from: www. planningportal.nsw.gov.au/major-projects/project/3611.

13. Harris P, Riley E, Dawson A, Friel S, Lawson K. "Stop talking around projects and talk about solutions": positioning health within infrastructure policy to achieve the sustainable development goals. Health Policy. 2020;124(6):591-8.

14. Infrastructure Australia. Record infrastructure spend the new normal, 2019 Australian Infrastructure Audit warns. Canberra: Infrastructure Australia; 2019 [cited 2019 Aug 19]. Available from: www.infrastructureaustralia.gov.au/ listing/media-release/record-infrastructure-spend-newnormal-2019-australian-infrastructure-audit-warns

15. Smith G, Wales C. Citizens' juries and deliberative democracy. In: d'Entreves M, editor. Democracy as public deliberation. Oxfordshire: Routledge; 2018. p. 157-177.

16. Boholm $\AA$. The public meeting as a theatre of dissent: risk and hazard in land use and environmental planning. Journal of Risk Research. 2008;11(1-2):119-40.

17. de Fine Licht J. Transparency actually: how transparency affects public perceptions of political decision-making. European Political Science Review. 2014;6(2):309-30.
18. Infrastructure NSW. WestConnex - Sydney's next motorway priority. Sydney: Infrastructure NSW; 2012 [cited 2019 Feb 19]. Available from: www.infrastructure.nsw.gov. au/media/1160/insw_tfnsw_and_roads_and_maritime_ services_wcx_25_sept_2012_final_120927.pdf

19. Infrastructure NSW. State infrastructure strategy. Bus and light rail in Sydney. Sydney: Infrastructure NSW; 2012 [cited 2019 Feb 19]. Available from: www.infrastructure. nsw.gov.au/media/1137/sis_report_section70_print.pdf

20. Australian Bureau of Statistics. Regional population growth, Australia, 2016-17. Canberra: ABS; 2018 [cited 2019 Feb 20]. Available from: www.abs.gov.au/ausstats/ abs@.nsf/lookup/3218.0Media\%20Release12016-17

21. The World Bank. Population growth (annual \%). Washington, DC: The World Bank; 2019 [cited 2019 Feb 20]. Available from: data.worldbank.org/indicator/SP.POP. GROW?end $=1960 \&$ start $=1960 \&$ view $=$ bar

22. Pucher J, Peng Zr, Mittal N, Zhu Y, Korattyswaroopam N. Urban transport trends and policies in China and India: impacts of rapid economic growth. Transport Reviews. 2007;27(4):379-410.

23. Daley J. Infrastructure choices: evaluation and politics. Perth: Grattan Institute; 2019 [cited 2019 Nov 12]. Available from: www.grattan.edu.au/wp-content/ uploads/2019/09/infrastructure-2019.pdf

24. Flyvbjerg B, Skamris Holm MK, Buhl SL. How (in)accurate are demand forecasts in public works projects?: The case of transportation. Journal of the American Planning Association. 2005;71(2):131-46.

25. Harris P, Kent J, Sainsbury P, Marie-Thow A, Baum F, Friel S, McCue P. Creating 'healthy built environment' legislation in Australia; a policy analysis. Health Promot Int. 2017;33(6):1090-100.

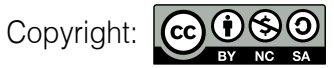

(c) 2021 Robertson et al. This article is licensed under the Creative Commons Attribution-NonCommercial-ShareAlike 4.0 International Licence, which allows others to redistribute, adapt and share this work non-commercially provided they attribute the work and any adapted version of it is distributed under the same Creative Commons licence terms. See: www.creativecommons.org/licenses/by-nc-sa/4.0/ 